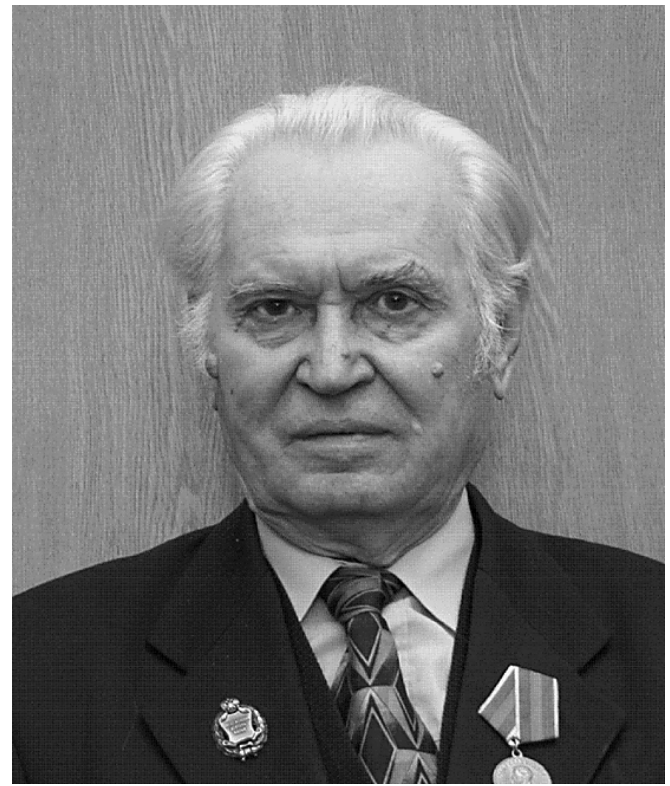

\title{
To the 80th Anniversary of Aleksandr Ivanovich Zhuravlev
}

DOI: $10.1134 / \mathrm{S} 0006350910060266$

January 28, 2010 Doctor of Biology, Honored Worker of Science of the RF, Professor Aleksandr Ivanovich Zhuravlev has seen 80.

The scientific activity of A.I. Zhuravlev began with a study of free-radical (per)oxidation of lipids in 1954 under supervision of Professor N.I. Kozin.

In 1956 he became a member of the laboratory of biophysics of the Institute of Biophysics, USSR Ministry of Health headed by professor B.N. Tarusov.

In 1961 the groups of researchers composed of: B.N. Tarusov, A.I. Polivoda, A.I. Zhuravlev discovered an ultraweak glow of animal tissues in the visible part of the spectrum, and this meant functioning therein of electronic excited states. The glow was fixed after creating a sensor of novel design - a photoelectric multiplier placed into liquid nitrogen not in a glass Dewar flask but in a foam-plastic vessel. This excluded absorption and scattering of the glow on 2 quartz windows and in the later of boiling liquid nitrogen, and this glow was registered from the surface of naked liver and brain of animals.

In 1961 A.I. Zhuravlev discovered spontaneous chemiluminescence of lipids during their free-radical oxidation. This effect, and also drastic weakening of the glow of homogenates of organs after extraction further on allowed making a conclusion that the spontaneous ultraweak glow of tissues is determined, mainly, by free-radical processes in lipids. Shown was a change of glow intensity, and this meant the level of electronic excited states in a series of pathologies, in particular, decline of glow and increase of antioxidative activity of tissues of some malignant tumors.

The sum of these investigations is generalized in the monograph "Quantum Biophysics of Animals and Man”, 2006, 2009.

From 1962 till 1972 A.I. Zhuravlev headed the laboratory of biophysics of the CSRI of Balneology of Physiotherapy, USSR MH.

In 1972 elected by contest as first Head of the Chair of biophysics of the Biological faculty, Moscow Veterinary Academy, which he headed until 2008. He, with disciples Yu.P. Dobrachev, V.B. Akopyan, V.E. Novikov, O.G. Yarosh, N.V. Nikol'skaya, M.V. Palei arranged an educational process by university programs and trained over 900 specialists in speciality "Biophysics" with qualification "veterinarian biophysicist".

As an optimistic person, he is sure that in the foundation of science there lies common sense based on the sense of humor.

Friends, disciples and colleagues from all their heart congratulate A.I. Zhuravlev with his jubilee and wish him many years of creative activity.

Colleagues, friends, disciples 